\title{
PENYALAHGUNAAN LETTER OF CREDIT DALAM PERDAGANGAN EKSPOR IMPOR UNTUK MELAKUKAN TRADE BASED MONEY LAUNDERING STUDI TERHADAP KASUS L/C FIKTIF BNI
}

\author{
Karbela $^{1}$
}

Abstrak

This article gives elaboration by analysis on fake letter of credit issuance at BNI. The letter of credit in false issued is categorized as trade based money laundering. The false is done by mark up method for export-import invoices as conditioned document of letter of credit why resulted increased goods price become more expensive. More of misuse of letter of credit that is aimed to money laundering practice known as predicate offences by counterfeit documents like truly international business transaction has been executed. The author does analysis to prove the using of false letter of credit was happened in BNI. The author opinion in BNI case can be regarded as trade based money laundering on letter of credit misused by made false of letter of credit documents and more the export import transaction itself.

Kata kunci: hukum dagang, letter of credit, pencucian uang, kasus bni

\section{Pendahuluan}

Setiap negara di dunia memiliki perbedaan-perbedaan atau ciri khas seperti letak geografi, ekologi, demografi, sumber daya alam, sampai hasil produksinya. ${ }^{2} \mathrm{Hal}$ tersebut mengakibatkan antara satu negara dengan negara lain saling membutuhkan untuk memenuhi kebutuhannya. Ada kalanya produksi yang dihasilkan suatu negara belum cukup dikonsumsi seluruhya di dalam negeri dan masih memerlukan bantuan negara lain untuk mengolahnya sehingga dapat diimpor dari negara lain atau sebaliknya konsumsi di dalam negeri sudah melebihi dari yang dibutuhkan sehingga dapat diekspor ke

${ }^{1}$ PNS pada Departemen Luar Negeri, Republik Indonesia, alamat korespondensi: karbela_rachman@yahoo.com.

${ }^{2}$ Hartono Hadisoeprapto, "Kredit Berdokumen (Letter of Credit): Cara Pembayaran dalam Jual Beli Perniagaan”, cet. 1, (Yogyakarta: Liberty, 1984), hal. 4. 
negara lain. Hal tersebut menimbulkan perdagangan antar negara yang disebut sebagai jual beli perniagaan atau ekspor-impor. ${ }^{3}$

Di beberapa literatur jual beli perniagaan dikenal dengan juga istilah jual beli perusahaan yaitu suatu perjanjian jual beli yang dilakukan pedagang atau atau pengusaha lainnya yang berdasarkan perusahaannya atau jabatannya melakukan perjanjian jual beli. ${ }^{4}$ Dalam hal ini, penjual dan pembeli biasanya berupa badan hukum atau perusahaan yang masing-masing terletak di negara yang berbeda. ${ }^{5}$

Jual beli adalah suatu perjanjian timbal balik antara penjual dengan pembeli di mana pihak penjual mengikatkan diri untuk menyerahkan benda dan pihak pembeli untuk membayar harga yang sudah diperjanjikan itu. ${ }^{6}$ Berdasarkan hal tersebut, timbul kewajiban yaitu penjual barang dan sebaliknya sebaliknya pembeli berkewajiban membayar.

Kewajiban penjual selain menyerahkan barang adalah juga menanggung pemakaian atas barang. ${ }^{7}$ Kewajiban menyerahkan barang pada hakekatnya menjadikan pembeli menjadi orang yang berhak atas benda itu (pemilik/eigenaar). ${ }^{8}$ Sedangkan kewajiban penjual untuk menanggung pemakaian atas barang berarti menjamin penguasaan barang dengan aman dan damai dari sengketa dengan pihak ketiga dan menjamin barang agar tidak cacat. ${ }^{9}$ Sebaliknya, kewajiban pembeli adalah membayar harga barang yang dibelinya dan memikul biaya-biaya pembuatan akta jual beli dan biayabiaya tambahan lainnya kecuali jika diperjanjikan sebaliknya. ${ }^{10}$

${ }^{3}$ Ibid., hal. 7 .

${ }^{4}$ H. M. N. Purwosutjipto, "Pengertian Hukum Dagang Indonesia: Hukum Jual Beli Perusahaan (4)", cet. 5, (Jakarta: Djambatan, 2003), hal. 1.

${ }^{5}$ Ibid., hal. 2.

${ }^{6}$ Kitab Undang-undang Hukum Perdata [Burgelijk Wetboek], diterjemahkan oleh R. Subekti dan R. Tjitrosudibio, cet. 33, (Jakarta: Pradnya Paramita, 2003), Pasal. 1457.

${ }^{7}$ Kitab Undang-undang Hukum Perdata [Burgelijk Wetboek], Op. Cit., Pasal. 1474.

${ }^{8}$ Ibid., Pasal. 1459.

${ }^{9}$ Ibid., Pasal. 1504

${ }^{10}$ Ibid., Pasal. 1513 dan Pasal. 1466. 
Berdasarkan penjelasan di atas, unsur pertama dalam jual beli adalah penyerahan yang dilakukan penjual dan unsur kedua adalah pembayaran yang dilakukan pembeli. ${ }^{11}$

Dalam penulisan ini, perjanjian jual beli yang dimaksud yaitu perjanjian jual beli perniagaan (ekspor-impor).

Unsur penyerahan dibedakan menjadi penyerahan benda bergerak dan benda tidak bergerak. Penyerahan kebendaan bergerak, dilakukan dengan penyerahan yang nyata. ${ }^{12}$ Penyerahan akan piutang-piutang dilakukan dengan pembuatan akta otentik atau di bawah tangan (piutang atas nama), penyerahan surat itu (piutang atas unjuk) dan penyerahan surat disertai dengan endosemen (piutang atas pengganti). ${ }^{13}$ Penyerahan atau penunjukan atas kebendaan tak bergerak dilakukan dengan pengumuman atas akta yang bersangkutan. $^{14}$ adalah: ${ }^{15}$

Sedangkan beberapa cara pembayaran yang dilakukan oleh importir,

a. Pembayaran di muka (Advance payment)

Advance payment adalah pembayaran yang dilakukan oleh importir kepada eksportir sebelum barang dikapalkan, baik untuk seluruh nilai barang (full payment) maupun untuk sebagian (partial payment). ${ }^{16}$ Cara pembayaran ini merugikan importir jika eksportir tidak mematuhi ketentuan pengiriman barang. ${ }^{17}$

b. Wesel Inkaso (Collection Draft)

${ }^{11}$ Purwosutjipto, Op. Cit., hal. 5.

${ }^{12}$ Ibid., Pasal. 612.

${ }^{13}$ Ibid., Pasal. 613 ayat (1) dan (3).

${ }^{14}$ Ibid., Pasal. 616.

15 Indonesia, Peraturan Pemerintah No.1 tahun 1982, Pasal.3 jo. Departemen Perdagangan dan Koperasi, Keputusan Menteri Perdagangan dan Koperasi tentang Tata Cara Pembayaran Ekspor dan Impor, No.27/KP/I/82.

${ }^{16}$ Soepriyo Andhibroto, "Letter of Credit: Dalam Teori dan Praktek", cet. 2 (Edisi revisi), (Semarang: Dahara Prize, 1997), hal.15.

${ }^{17}$ Edward G. Hinkelman, "A Short Course in International Payments", (California: World Trade Press, 1999), hal. 12. 
Collection Draft adalah pembayaran dengan cara mengirim dokumen dari eksportir kepada importir dengan menggunakan jasa bank berupa wesel (draft) atau promissory notes untuk menagih pembayarannya, baik dengan menggunakan draft ataupum promissory notes. Cara ini meliputi: ${ }^{18}$

1. Documentary collection, yaitu pengiriman seluruh dokumen untuk ditagihkan atas dasar:

a) pembayaran tunai (Documents againts Payment);

b) akseptasi atas wesel berjangka atau promes (Documents againts Acceptance).

2. Clean (bill) collection, yaitu pengiriman wesel atau promes saja untuk ditagihkan.

Cara ini memberikan resiko bagi eksportir dan importir. Eksportir tidak mendapat pembayaran sampai pengiriman barang dilakukan. Sebaliknya importir dirugikan jika eksportir mengirim barang yang salah. ${ }^{19}$

\section{Perhitungan kemudian (Open Account)}

Open Account adalah pembayaran yang mensyaratkan bahwa importir akan melunasi pembayaran di kemudian hari pada tanggal yang sudah disepakati. ${ }^{20}$ Cara ini merugikan eksportir jika importir tidak mematuhi (not comply with) ketentuan pembayaran yang disepakati. ${ }^{21}$

\section{Konsinyasi (Consignment)}

Consignment adalah pembayaran dengan menitip barang ekspor kepada suatu pihak di luar negeri untuk dijualkan. ${ }^{22}$ Eksportir tetap memegang hak milik atas barang dan pembayaran baru dilakukan kalau barang telah laku terjual di

\footnotetext{
${ }^{18}$ Andhibroto, Op. Cit., hal. 16.

${ }^{19}$ Hinkelman, Op. Cit., hal. 14.

${ }^{20}$ Andhibroto, Op. Cit., hal. 18.

${ }^{21}$ Hinkelman, Op. Cit., hal. 15.

${ }^{22}$ Andhibroto, Op. Cit., hal. 19.
} 
negara pengimpor. ${ }^{23}$ Cara ini merugikan eksportir karena kemungkinan barang terlalu lama bertahan sampai terjual.

c. Kredit berdokumen (Letter of Credit)

Letter of Credit $(L / C)$ adalah pembayaran yang dilakukan berdasarkan dokumen pengapalan barang, maka sering disebut Documentary Letter of Credit, yakni pembayaran L/C yang dijamin dengan dokumen. ${ }^{24}$ Cara ini menguntungkan eksportir dan importir karena adanya peran bank dalam menjamin pengiriman barang dan pembayaran harga. ${ }^{25}$

Berdasarkan cara pembayaran di atas, ternyata cara pembayaran yang dianggap paling melindungi para pihak adalah cara pembayaran dengan menggunakan $L / C{ }^{26} \mathrm{Hal}$ ini disebabkan penggunaan $\mathrm{L} / \mathrm{C}$ memberikan kemudahan bagi semua pihak, termasuk bank yang hanya berurusan dengan dokumen, bukan dengan barang, jasa, atau penggunaannya lainnya yang berkaitan dengan dokumen bersangkutan. ${ }^{27}$

Sampai saat ini belum ada ketentuan khusus yang bersifat memaksa berlaku di seluruh dunia mengenai penggunaan $\mathrm{L} / \mathrm{C}{ }^{28}$ Namun, organisasi perdagangan dan dunia perbankan yang tergabung dalam organisasi International Chamber of Commerce (ICC) telah membuat suatu ketentuan yang telah tersebar luas dan terkenal secara internasional yaitu Uniform Customs and Practices for Documentary Credits (UCP) Publication No. 500 atau UCP 500 yang telah mengalami revisi beberapa kali yang terakhir yaitu UCP $600 .^{29}$ Walaupun ketentuan UCP 600 tidak bersifat memaksa tetapi diikuti oleh beberapa perusahaan.

${ }^{23}$ Hadisoeprapto, Op. Cit., hal. 21.

${ }^{24}$ Andhibroto, Op. Cit., hal. 21.

${ }^{25}$ Hinkelman, Op. Cit., hal. 11.

${ }^{26}$ Andhibroto, Op. Cit., hal. 7.

${ }^{27}$ DEdy Ihsan dan Doddy Aprilachtieno, Di Mana Letak Kesalahan BNI? Bagian Pertama dari Dua Tulisan, <http://www.bisnis.com>, diakses tanggal 12 Maret 2007.

${ }^{28}$ Rolf A. Schutze dan Gabriele Fontane, "Documentary Credit Law Throughout the World", (Paris: ICC Publishing, S.A., 2001), hal. 11.

29 International Chamber of Commerce: Indonesia National Committe, $<\mathrm{http}$ ://iccindonesia.org/index.php?option $=$ com_content\&task=view\&id=14\&Itemid=2>, diakses tanggal 22 November 2007. 
Namun, apabila dalam suatu negara terdapat ketentuan khusus yang mengatur L/C maka para pihak dapat menyepakati bahwa ketentuan UCP bersifat melengkapi ketentuan nasional. Selain itu, para pihak memiliki kebebasan untuk membuat ketentuan perjanjian sendiri di mana ketentuan UCP dapat melengkapi ketentuan perjanjian yang dibuat para pihak. ${ }^{30}$

Dalam praktek pembayaran $\mathrm{L} / \mathrm{C}$, tidak tertutup kemungkinan terjadi penyimpangan dokumen dari syarat dan kondisi yang telah ditetapkan misalnya L/C yang diterbitkan bukan dari bank koresponden, diskonto dilakukan sebelum akseptasi dari Issuing Bank, sampai dengan pemalsuan dokumen $\mathrm{L} / \mathrm{C}$. $^{31}$

Apabila, penyimpangan tersebut tidak ditindaklanjuti maka dana yang dihasilkan dari pemalsuan dokumen $\mathrm{L} / \mathrm{C}$ tersebut akan dapat dicairkan. Dana tersebut pada umumnya tidak langsung digunakan tetapi dimasukan ke dalam sistem keuangan (placement). ${ }^{32}$ Tindakan inilah yang dikenal dengan istilah trade based money laundering. ${ }^{33}$

Berdasarkan kenyataan di atas terdapat pandangan bahwa dunia perbankan juga rentan atas tindak pidana terorganisir sehingga sangat strategis untuk dimanfaatkan. Tindakan placement biasanya bersembunyi di balik suatu nama perusahaan atau nama lain (nominees) dengan melakukan perdagangan internasional fiktif yang berskala besar. ${ }^{34}$ Perusahaan yang digunakan untuk menyembunyikan kegiatan tindakan layering tersebut biasanya meminta kredit/pembiayaan dari bank untuk menyamarkan aktivitas pencucian uang atau menggunakan faktur (invoice) palsu yang di mark up atau L/C palsu sebagai upaya untuk menyulitkan pengusutan kemudian. ${ }^{35}$ Salah satu kasus yang terjadi di Indonesia yaitu pengucuran dana Bank Nasional Indonesia (BNI) sebesar 1,7 trilyun yang ternyata tidak digunakan

6.

${ }^{30}$ Michael Rowe, "Letter of Credit", (London: Euromoney Publications, 1985), hal.

${ }^{31}$ TEdy Ferdiansyah Idris, Buruknya Manajemen Risiko Biang Kerok Bobolnya L/C BNI, <http://www.kompas.com>, diakses tanggal 12 Maret 2007.

32 Pedoman Umum Pencegahan dan Pemberantasan Tindak Pidana Pencucian Uang bagi Penyedia Jasa keuangan, <http://www.bapepam.go.id/old/ragam/pedoman pencucian_uang.pdf $>$, diakses tanggal 8 Februari 2007.

${ }^{33}$ Financial Action Task Force/Groupe d'Action Financiere, Trade based Money Laundering, <http://www.fatf-gafi.org/dataoecd/60/25/37038272.pdf>, diakses tangggal 27 Oktober 2007.

\footnotetext{
${ }^{34}<$ http://www.bapepam.go.id/old/ragam/pedoman_pencucian_uang.pdf $>$,Op.Cit.

${ }^{35}$ Ibid.
} 
untuk pembayaran ekspor tetapi digunakan untuk proyek yang tidak sesuai dengan permohonan $\mathrm{L} / \mathrm{C}$. $^{36}$

Berdasarkan paparan di atas, penulis tertarik untuk meneliti lebih lanjut tentang penggunaan $\mathrm{L} / \mathrm{C}$ dan kaitannya dengan tindak pidana pencucian uang.

\section{Rumusan Permasalahan}

Adapun beberapa masalah yang akan dikaji, adalah:

1. Bagaimana penggunaan $\mathrm{L} / \mathrm{C}$ dalam perdagangan ekspor impor dapat dianggap sebagai bentuk Money Laundering?

2. Apakah penggunaan $\mathrm{L} / \mathrm{C}$ pada kasus L/C Fiktif BNI dapat dikategorikan sebagai Money Laundering?

\section{Metode Penelitian}

Metode Penelitian ini menggunakan metode penelitian yuridis normatif, yakni dengan menggunakan bahan-bahan kepustakaan yang bersifat deskriptif. ${ }^{37}$

Adapun data yang digunakan adalah data primer dan data sekunder. ${ }^{38}$ Data primer adalah data yang langsung diperoleh dari masyarakat yaitu berupa wawancara oleh narasumber. ${ }^{39}$ Sedangkan data sekunder adalah data yang berasal dari studi literatur yang terdiri dari: ${ }^{40}$

1. Bahan hukum Primer, yang berupa Peraturan Perundangundangan

2. Bahan Hukum Sekunder, yang berupa media massa, internet, buku-buku, artikel mengenai pembayaran menggunakan L/C dan tindak pidana pencucian uang.

${ }^{36}$ Mulyanto, "Pembuktian Terbalik dalam Tindak Pidana Pencucian Uang", Varia Peradilan: Majalah Hukum tahun ke XXII No. 254 (Januari 2007): 40.

37 Sri Mamudji, dan Hang Raharjo., "Metode Penelitian dan Penulisan Hukum", (Jakarta: Badan Penerbit Fakultas Hukum Universitas Indonesia, 2005), hal. 5.

$$
\begin{aligned}
& { }^{38} \text { Ibid. } \\
& { }^{39} \text { Ibid. } \\
& { }^{40} \text { Ibid. }
\end{aligned}
$$




\section{Posisi Kasus}

Kasus ini terjadi di kantor BNI Kebayoran Baru (selanjutnya disebut BNI Kebayoran Baru) di mana Drs. Koesadiyuwono bertindak selaku pimpinan cabang dan Drs. Edy Santoso (selanjutnya disebut Edy) bertindak selaku Customer Service Manager Luar Negeri (CSMLN). Kedua pejabat BNI Kebyoran Baru tersebt telah melakukan pendiskontoan terhadap $37 \mathrm{~L} / \mathrm{C}$ dari Gramarindo Group dengan mengabaikan ketentuan transaksi ekspor yang berlaku pada PT. Bank BNI (Persero) Tbk dan ketentuan ekspor. milik:

Hal tersebut berawal dari adanya L/C yang tidak terbayar/unpaid

1. PT. Mahesa dengan Direktur Utama Rudi Sutopo;

2. PT. Petindo dendan Direktur Utama John Hamenda; dan

3. PT. Prasetya Cipta Tulada dengan direktur Yani Sumarsono yang diproses oleh Edy, yang seharusnya jatuh tempo pada bulan Desember 2002.

Untuk menutup transaksi L/C yang tidak terbayar tersebut, Edy meminta kepada Drs. Aprilia Widharta, yang saat itu menjabat sebagai Direktur Operasional PT. Mahesa, agar dipertemukan dengan Maria Pauline Lumowa (selanjutnya disebut Maria), yang memiliki dan menguasai sebagian besar saham Gramarindo Group, untuk membantu pembayaran/penutupan/ pelunasan L/C yang tidak terbayar tersebut.

Edy kemudian menawarkan dana atau skema pendanaan yang lebih cepat realisasinya, yakni dengan menggunakan fasilitas Wesel Ekspor Diskonto dari BNI Kebayoran Baru, dan hasil pendiskontoan wesel ekspor itu selain digunakan untuk menutup L/C yang tidak terbayar tersebut juga dapat digunakan untuk membiayai usaha marmer milik Maria di Kupang. Atas tawaran Edy tersebut, Maria menyetujuinya.

Selanjutnya Edy menjelaskan kepada Maria dan Aprilia Widharta bahwa dirinya yang akan menyediakan seluruh dokumen ekspor diskonto tersebut, seperti dokumen invoice, packing list, wight list, insurance, B/L kontrak jual beli, termasuk L/C yang disewa dari Singapura.

Untuk menampung/menerima dana hasil pendiskontoan $\mathrm{L} / \mathrm{C}$ tersebut, Edy meminta Maria agar menyiapkan beberapa perusahaan yang seolah-olah melakukan kegiatan ekspor, yaitu ekspor pasir. Atas permintaan Edy, Maria kemudian meminta masing-masing Direktur Utama/Direktur dari perusahaan eksportir tersebut untuk membuka rekening giro pada BNI Kebayoran Baru yang nantinya manampung dana pendiskontoan L/C ekspor yang mereka ajukan. Rekening giro tersebut adalah: 
1. PT. Gramarindo Mega Indonesia (Ir. Ollah Abdullah Agam) membuka rekening:

a. Rupiah No.022.000227995.001 tanggal 20 September 2002;

b. USD No.022.000227995.002 tanggal 29 September 2002;

c. EURO No.022.000227995.003 tanggal 19 Juni 2003.

2. PT. Magnetiq Usaha Esa Indonesia (Adrian Pandelaki Lumowa) membuka rekening:
a. Rupiah No.022.000293572.001 tanggal 28 Januari 2003;
b. USD No.022.000293572.002 tanggal 30 Januari 2003;
c. EURO No.022.000293572.003 tanggal 6 Juni 2003.

3. PT. Bhinekatama Pasific (Dr. Titik Prostiwanti) membuka rekening:
a. Rupiah No.022.000292039.001 tanggal 28 Januari 2003;
b. USD No.022.000292039.002 tanggal 28 Januari 2003;
c. EURO No.022.000292039.003 tanggal 11 Juni 2003.

4. PT. Basomasindo (Judi Baso) membuka rekening:
a. Rupiah No.022.000320832.001 tanggal 8 Mei 2003;
b. USD No.022.000320832.002 tanggal 14 Mei 2003.

5. PT. Triranu Caraka Pasific (Ir. Jeffrey Baso) membuka rekening:

a. Rupiah No.022.000223250.001 tanggal 18 November 2002;

b. USD No.022.000223250.002 tanggal 2 Agustus 2002 .

6. PT. Pan Kifros (Drs. Aprilia Widharta) membuka rekening:

a. Rupiah No.022.000227995.001 tanggal 21 Agustus 2002;

b. USD No.022.000222525.002 tanggal 21 Agustus 2002.

7. PT. Metrantara (Richard Kuontul) membuka rekening:

a. Rupiah No.022.000326799.001 tanggal 10 Juli 2003;

b. USD No.022.000326799.002 tanggal 30 Januari 2003;

c. EURO No.022.000326799.003 tanggal 6 Juni 2003.

Bahwa kenyataannya ketentuan-ketentuan tersebut oleh Koesadiyuwono dan Edy tidak dilaksanakan mengingat dokumen-dokumen ekspor berupa packing list, invoice, weight list, bill of lading, insurance certificate yang harus disiapkan para perusahaan eksportir tersebut sesuai dengan ketentuan L/C ternyata disiapkan oleh Edy. Kemudian masingmasing Dirut/Direktur dari perusahaan tersebut menandatangani dokumen ekspor tersebut walaupun mereka mengetahui bahwa perusahaannya tidak melakukan ekspor.

Selanjutnya dokumen-dokumen ekspor yang tidak benar dan tidak disertai Pemberitahuan Ekspor Barang (PEB) diajukan kepada PT. Bank BNI (Persero) Tbk. Selain itu, dokumen-dokumen ekspor tersebut ternyata memiliki banyak sekali penyimpangan/discrepancy setelah dilakukan penelitian oleh asisten dan penyelia. Penyelia mengusulkan kepada EDY 
berupa catatan pada work sheet diskonto under L/I proceed blokir $100 \%$ sampai kredit nota masuk.

Terhadap adanya discrepany itu, Edy tidak meminta eksportir untuk mengamandemen dokumen ekspor tersebut dan melakukan akseptasi kepada issuing bank. Tanpa memberikan usulan kepada Koesadiyuwono, Edy memerintahkan penyelia agar langsung mendiskonto dana $\mathrm{L} / \mathrm{C}$ tersebut kemudian dikreditkan ke masing-masing rekening perusahaan tersebut.

Adapun L/C yang diterima oleh PT. Bank BNI (Persero) Tbk tersebut antara lain:

1. L/C yang diajukan PT. Gramarindo Mega Indonesia:

a. L/C No.DOC/101019 senilai USD 3.000.800.- pada tanggal 26 Maret 2003.

Dengan ketentuan, Bank Switzerland sebagai issuing bank dan BNI Divisi Internasional sebagai advising bank serta tanggal negosiasi 9 April 2003. Dalam L/C ini terdapat discrepancy berupa dokumen perubahan (amandemen) tidak dilampirkan.

b. L/C No.DBK/LC/1155/03 senilai USD 3.000.000.- pada tanggal 16 April 2003.

Dengan ketentuan Dubai Bank Kenya sebagai issuing bank dan Standard Chartered Bank sebagai advising bank serta tanggal negosiasi 17 Juli 2003. Dalam L/C ini terdapat discrepancy berupa alamat issuing bank dalam draft tidak ada, dokumen L/C asli yang dikirim ke issuing bank tidak dilampiri dengan original courier receipt dari DHL.

c. L/C No.DBK/LC/01255/03 senilai USD 3.000.000.- pada tanggal 24 April 2003.

Dengan ketentuan Dubai Bank Kenya sebagai issuing bank dan Standard Chartered Bank sebagai advising bank serta tanggal negosiasi 29 April 2003. Dalam L/C ini terdapat discrepancy berupa alamat issuing bank dalam draft tidak ada, dokumen L/C asli yang dikirim ke issuing bank tidak dilampiri dengan original courier receipt dari DHL.

d. L/C No.LCMEBK 1091/03 senilai USD 1.800.000.- pada 5 Mei 2003.

Dengan ketentuan Middle East Bank Kenya sebagai issuing bank dan Standard Chartered Bank sebagai advising bank 
serta tanggal negosiasi 12 Mei 2003. Dalam L/C ini terdapat discrepancy berupa copy swift/telex dari issuing bank melalui advising bank atas penunjukan kapal dari applicant tidak dilampirkan dalam dokumen.

e. L/C No.MEBK 1092/03 senilai USD 1.999.996.- pada tanggal 5 Mei 2003.

Dengan ketentuan Middle East Bank Kenya sebagai issuing bank dan Standard Chartered Bank sebagai advising bank serta tanggal negosiasi $12 \mathrm{Mei} 2003$. Dalam L/C ini terdapat discrepancy berupa authenticated swift messages dan nominated wessel dari issuing bank tidak ada.

f. L/C No.MEBK 1094/03 senilai USD 1.999.999.93 pada tanggal 9 Mei 2003.

Dengan ketentuan Middle East Bank Kenya sebagai issuing bank dan Standard Chartered Bank sebagai advising bank. Dalam L/C ini terdapat discrepancy berupa nominated wessel begi applicant dan authorized signature dari bank tidak ada.

g. L/C No.MEBK 1093/03 senilai USD 1.999.999.96 pada tanggal 9 Mei 2003.

Dengan ketentuan Middle East Bank Kenya sebagai issuing bank dan Standard Chartered Bank sebagai advising bank serta tanggal negosiasi $20 \mathrm{Mei} 2003$. Dalam L/C ini terdapat discrepancy berupa nominated wessel begi applicant dan authorized signature dari bank tidak ada.

h. L/C No.DBK/LC/ACCP22/03 senilai EUR 4.325.000 pada tanggal 3 Juni 2003.

Dengan ketentuan Dubai Bank Kenya sebagai issuing bank dan ABN Amro Bank sebagai advising bank serta tanggal negosiasi 19 Juni 2003. Dalam L/C ini terdapat discrepancy berupa pelabuhan tujuan tidak jelas.

2. L/C yang diajukan PT. Magnetiq Usaha Esa Indonesia:

a. L/C No.WSBC/SLC/A137/03 senilai USD 4.999.998.- pada tanggal 5 Februari 2003.

Dengan ketentuan Dubai Bank Kenya sebagai issuing bank dan Standard Chartered Bank sebagai advising bank serta tanggal negosiasi 23 Februari 2003. Dalam L/C ini terdapat 
discrepancy berupa nilai harga yang tercantum dalam dokumen ekspor tidak sesuai dengan $\mathrm{L} / \mathrm{C}$.

b. L/C No.DBK/LC/0002/03 senilai USD 2.250.000.- pada tanggal 21 Maret 2003.

Dengan ketentuan Dubai Bank Kenya sebagai issuing bank dan Standard Chartered Bank sebagai advising bank serta tanggal negosiasi 3 Maret 2003. Dalam L/C ini terdapat discrepancy berupa invoice tidak di counter sign oleh applicant dan tidak ada verifikasi dari issuing bank.

c. L/C No.DBK/LC/003/03 senilai USD 2.178.000.- pada tanggal 21 Maret 2003.

Dengan ketentuan Dubai Bank Kenya sebagai issuing bank dan Standard Chartered Bank sebagai advising bank serta tanggal negosiasi 31 Maret 2003. Dalam L/C ini terdapat discrepancy berupa beneficiare statement document non negotiable telah dikirim kepada applicant dan courier receipts tidak terlampir dalam dokumen.

d. L/C No.DBK/LC/0007/03 senilai USD 3.000.000.- pada tanggal 30 Maret 2003

Dengan ketentuan Dubai Bank Kenya sebagai issuing bank dan Standard Chartered Bank sebagai advising bank serta tanggal negosiasi 10 April 2003. Dalam L/C ini terdapat discrepancy berupa inspection certificate dan dokumen amandemen tidak ada.

e. L/C No.DOC/LC/1010.23 senilai USD 2.000.000.- pada tanggal 8 April 2003.

Dengan ketentuan Ross Bank Switzerland sebagai issuing bank dan American Express Bank sebagai advising bank serta tanggal negosiasi 15 April 2003. Dalam L/C ini terdapat discrepancy berupa authentic swift/telex tidak dilampirkan.

f. L/C No.DBK/LC/11SS/03 senilai USD 3.000.000.- pada tanggal 16 April 2003.

Dengan ketentuan Dubai Bank Kenya sebagai issuing bank dan Standard Chartered Bank sebagai advising bank serta tanggal negosiasi 23 April 2003. Dalam L/C ini terdapat discrepancy berupa alamat issuing bank dalam draft tidak 
ada, dokumen L/C yang asli tidak dikirim ke issuing bank dan tidak dilampiri dengan original courier receipt dari DHL.

g. L/C No.DBK/LC/14ACCP/03 senilai USD 2.999.999.59 pada tanggal 12 Mei 2002.

Dengan ketentuan Dubai Bank Kenya sebagai issuing bank dan ABN Amro Bank sebagai advising bank serta tanggal negosiasi 29 Mei 2003. Dalam L/C ini terdapat discrepancy berupa dokumen amandemen tidak dilampirkan.

h. L/C No.WSBC/LC/A5919/03 senilai USD 4.000.000.- pada tanggal 16 Mei 2003.

Dengan ketentuan Wall Street Bank sebagai issuing bank dan Bank Mega sebagai advising bank serta tanggal negosiasi 23 Mei 2003. Dalam L/C ini terdapat discrepancy berupa alamat issuing bank dalam draft tidak ada.

i. L/C No.DBK/LC/ACCP19/03 senilai EUR 4.025.000 pada tanggal 28 Mei 2003.

Dengan ketentuan Dubai Bank Kenya sebagai issuing bank dan Standard Chartered Bank sebagai advising bank serta tanggal negosiasi 6 Juni 2003. Dalam L/C ini terdapat discrepancy berupa copy authentic swift/telex dari opening bank atas penunjukan nominated wessel tidak dilampirkan.

j. L/C No.DBK/LC/ACCP28/03 senilai EUR 6.000.000 pada tanggal 17 Juli 2003.

Dengan ketentuan Dubai Bank Kenya sebagai issuing bank dan Standard Chartered Bank sebagai advising bank serta tanggal negosiasi 17 Juli 2003. Dalam L/C ini terdapat discrepancy berupa doc clean.

3. L/C yang diajukan PT. Bhinekatama Pasific:

a. L/C No.DBK/LC/0004/03 senilai USD 2.100.000.- pada tanggal 21 Maret 2003.

Dengan ketentuan Dubai Bank Kenya sebagai issuing bank dan Standard Chartered Bank sebagai advising bank serta tanggal negosiasi 31 Maret 2003. Dalam L/C ini terdapat discrepancy berupa invoice tidak ditandatangani oleh applicant. 
b. L/C No.DBK/LC/0006/03 senilai USD 3.000.000.- pada tanggal 30 Maret 2003.

Dengan ketentuan Dubai Bank Kenya sebagai issuing bank dan Standard Chartered Bank sebagai advising bank serta tanggal negosiasi 10 April 2003. Dalam L/C ini terdapat discrepancy berupa inspection sertificate dan dokumen amandemen tidak ada.

c. L/C No.DOC.101025 senilai USD 2.000.000.- pada tanggal 9 April 2003.

Dengan ketentuan Ross Bank Switzerland sebagai issuing bank dan American Express Bank sebagai advising bank serta tanggal negosiasi 15 April 2003. Dalam L/C ini terdapat discrepancy berupa inspection sertificate dari applicant dan verifikasi issuing bank serta authentic swift dari opening bank tidak dilampirkan dalam dokumen.

d. L/C No.DBK/LC/13SS/03 senilai USD 3.000.000.- pada tanggal 24 April 2003.

Dengan ketentuan Dubai Bank Kenya sebagai issuing bank dan $\mathrm{ABN}$ Amro Bank sebagai advising bank serta tanggal negosiasi 29 April 2003. Dalam L/C ini terdapat discrepancy berupa alamat issuing bank dalam draft tidak ada, dokumen $\mathrm{L} / \mathrm{C}$ asli yang dikirim ke issuing bank tidak dilampiri dengan original courier receipt dari DHL.

e. L/C No.DBK/LC/ACCP16/03 senilai USD 2.999.999.95 pada tanggal 9 Mei 2003.

Dengan ketentuan Dubai Bank Kenya sebagai issuing bank dan Standard Chartered Bank sebagai advising bank serta tanggal negosiasi 29 Mei 2003. Dalam L/C ini terdapat discrepancy berupa dokumen amandemen tidak ada, copy authentic swift dari issuing bank tidak dilampirkan.

f. L/C No.DBK/LC/17ACCP/03 senilai USD 3.000.000.- pada tanggal 12 Mei 2003.

Dengan ketentuan Dubai Bank Kenya sebagai issuing bank dan Standard Chartered Bank sebagai advising bank serta tanggal negosiasi 13 Juni 2003. Dalam L/C ini terdapat discrepancy berupa authenticated swift message dari issuing bank tidak ada. 
g. L/C No.DBK/LC/ACCP20/03 senilai EUR 4.235.000 pada tanggal 28 Mei 2003.

Dengan ketentuan Dubai Bank Kenya sebagai issuing bank dan ABN Amro Bank sebagai advising bank serta tanggal negosiasi 13 Juni 2003. Dalam L/C ini terdapat discrepancy berupa Bill of Lading $(B / L)$ tidak dilampirkan dalam dokumen.

4. L/C yang diajukan PT. Basomasindo:

a. L/C No.DBK/LC/ACCP15/03 senilai USD 3.000.000.- pada tanggal 8 Mei 2003.

Dengan ketentuan Dubai Bank Kenya sebagai issuing bank dan Standard Chartered Bank sebagai advising bank serta tanggal negosiasi $27 \mathrm{Mei}$ 2003. Dalam L/C ini terdapat discrepancy berupa copy aunticated certificate tidak ada.

b. L/C No.DOC 101029 senilai USD 2.000.000.- pada tanggal 14 Mei 2003.

Dengan ketentuan Ross Bank Switzerland sebagai issuing bank dan HSBC sebagai advising bank serta tanggal negosiasi 25 Mei 2003. Dalam L/C ini terdapat discrepancy berupa inspection certificate dari applicant dan verifikasi dari issuing bank tidak ada.

c. L/C No.WBSC/LC/A5917/03 senilai USD 3.000.000.- pada tanggal 16 Mei 2003.

Dengan ketentuan Wall Street Bank sebagai issuing bank dan Bank Bumiputera sebagai advising bank serta tanggal negosiasi 23 Mei 2003. Dalam L/C ini terdapat discrepancy berupa copy swift/telex dari issuing bank melalui advising bank atas menunjukan kapal dari applicant tidak dilampirkan dalam dokumen.

d. L/C No.DBK/LC/ACCP31/03 senilai EUR 7.245.000 pada tanggal 2 Juli 2003.

Dengan ketentuan Dubai Bank Kenya sebagai issuing bank dan American Express Bank sebagai advising bank serta tanggal negosiasi 17 Juli 2003. Dalam L/C ini terdapat discrepancy berupa doc clean. 
5. L/C yang diajukan PT. Triranu Caraka Pasific:

a. L/C No.WSBC/LC/A5634/02 senilai USD 2.238.500.- pada tanggal 24 Desember 2002.

Dengan ketentuan Wall Street Cook Island sebagai issuing bank dan ABN Amro Bank sebagai advising bank serta tanggal negosiasi 16 Desember 2002. Dalam L/C ini terdapat discrepancy berupa inspection certificate dari applicant untuk memeriksa barang dan verifikasi issuing bank tidak dilampirkan dalam dokumen.

b. L/C No.DBK/LC/ACCP18/03 senilai USD 4.025.000.- pada tanggal 12 Mei 2003.

Dengan ketentuan Dubai Bank Kenya sebagai issuing bank dan ABN Amro Bank sebagai advising bank serta tanggal negosiasi 27 Mei 2003. Dalam L/C ini terdapat discrepancy berupa authenticated swept message dari issuing bank tidak ada.

c. L/C No.WSBC/LC/A5918/03 senilai USD 3.599.999,87 pada tanggal 16 Mei 2003.

Dengan ketentuan Wall Street Cook Island sebagai issuing bank dan ABN Amro Bank sebagai advising bank serta tanggal negosiasi 28 Mei 2003. Dalam L/C ini terdapat discrepancy berupa inspection certificate dari applicant untuk memeriksa barang dan verifikasi issuing bank tidak dilampirkan dalam dokumen.

d. L/C No.DBK/LC/029/03 senilai EUR 5.445.000.- pada tanggal 2 Juli 2003.

Dengan ketentuan Dubai Bank Kenya sebagai issuing bank dan Standard Chartered Bank sebagai advising bank serta tanggal negosiasi 17 Juli 2003. Dalam L/C ini terdapat discrepancy berupa doc clean.

6. L/C yang diajukan PT. Pan Kifros pada tanggal 3 Desember 2002:

a. L/C No.WSBC/LC/A5627/02 senilai USD 2.178.000.-

b. L/C No.WSBC/LC/A5626/02 senilai USD 1.000.000.-

Dengan ketentuan Wall Street Bank sebagai Issuing Bank dan Standard Chartered Bank sebagai advising bank serta tanggal negosiasi 16 Desember 2002. Dalam L/C ini terdapat 
discrepancy berupa copy swift/telex tentang $\mathrm{L} / \mathrm{C}$ tidak dilampirkan dalam dokumen.

7. L/C yang diajukan PT. Pery Masterindo:

L/C No.DBK/LC/023/03 senilai EUR 4.500 .000 pada tanggal 11 Juni 2003. Dengan ketentuan Dubai Bank Kenya sebagai issuing bank dan ABN Amro Bank sebagai advising bank serta tanggal negosiasi 30 Juni 2003. Dalam L/C ini terdapat discrepancy berupa invoice tidak di counter sight oleh applicant dan tidak diverifikasi.

8. L/C yang diajukan PT. Metrantara:

L/C No.DBK/LC/027M/03 senilai EUR 4.830 .000 pada tanggal 2 Juli 2003. Dengan ketentuan Dubai Bank Kenya sebagai issuing bank dan Standard Chartered Bank sebagai advising bank serta tanggal negosiasi 17 Juli 2003. Dalam L/C ini terdapat discrepancy berupa doc clean.

Dari pembayaran semua $\mathrm{L} / \mathrm{C}$ di atas, masing-masing perusahaan telah memperoleh transfer dana dalam mata uang rupiah sejumlah:

1. PT. Gramarindo Mega Indonesia sejumlah Rp.69.357.694.579,-

2. PT. Magnetiq Usaha Esa Indonesia sejumlah Rp. 308.245.853.770,-

3. PT. Bhinekatama Pasific sejumlah Rp.178.597.801.663,--

4. PT. Basomasindo sejumlah Rp.132.455.525.835,-

5. PT. Triranu Caraka Pasific sejumlah Rp.132.114.708.938,-

6. PT. Pan Kifros sejumlah 28.220.640.000,-

7. PT. Pery Masterindo sejumlah Rp.42.513.750.000,-

8. PT. Metrantara sejumlah Rp.44.407.020.000,-

Apabila seluruh dana tersebut dijumlah maka besarnya adalah Rp.1.039.912.994.784,-

Berdasarkan tindakan yang dilakukan terdakwa Koesadiywoyo dan Eddy Santoso, mereka oleh Penuntut Umum didakwa:

1. Primair, pasal 2 ayat (1) jo pasal 18 UU No. 31 Tahun 1999 jo. UU No. 20 Tahun 2001 tentang Pemberantasan Tindak Pidana Korupsi jo pasal 55 ayat (1) angka 1 jo pasal 66 ayat (1) KUHP;

2. Subsider, pasal 3 jo pasal 18 UU No. 31 Tahun 1999 jo. UU No. 20 Tahun 2001 tentang Pemberantasan Tindak Pidana Korupsi jo. pasal 55 ayat (1) angka 1 jo pasal 64 ayat (1) KUHP;

3. Lebih Subsider, Pasal 49 ayat (2) huruf a UU No.7 Tahun 1992 jo No.10 Tahun 1998 tentang Perbankan jo. pasal 55 ayat (1) angka 1 jo pasal 64 ayat (1) KUHP; 
4. Lebih Subsider Lagi, Pasal 49 ayat (2) huruf b UU No.7 Tahun 1992 jo No.10 Tahun 1998 tentang Perbankan jo. pasal 55 ayat (1) angka 1 jo pasal 64 ayat (1) KUHP.

Berdasarkan Putusan No.566/Pid.B/2004/PN.Jak-Sel., terdakwa Koesadiyuwono dan Eddy Santoso terbukti secara sah dan meyakinkan bersalah melakukan tindak pidana "Turut sera melakukan Tindak Pidana Korupsi yang dilakukan secara berlanjut," sebagaimana dalam dakwaan primair. Menghukum terdakwa Koesadiyuwono dengan pidana penjara selama 16 tahun dan menghukum terdakwa Eddy Santoso dengan pidana penjara selama seumur hidup.

\section{Permasalahan}

Berdasarkan posisi kasus yang telah dijelaskan di atas terdapat beberapa permasalahan adalah:

1. Dari ke $37 \mathrm{~L} / \mathrm{C}$ yang telah didiskonto tersebut terdapat kejanggalan antara lain:

a. terdapat discrepancy;

b. Issuing Bank $L / C$ adalah bukan bank koresponden (non corespondence bank);

c. nasabah (eksportir) bukan nasabah debitur dan regular buyer.

2. Selain itu Perusahaan yang tergabung dalam Gramarindo Group tersebut bukan eksportir karena perusahaan tersebut ternyata tidak melakukan kegiatan ekspor.

3. Perusahaan pelayaran yang tercantum dalam Bill of Lading tidak pernah mengirim barang atas pesanan Gramarindo Group dan tidak pernah menandatangani Bill of Lading sebagai dokumen yang harus dilengkapi dalam $\mathrm{L} / \mathrm{C}$.

4. BNI Kebayoran Baru membayar dokumen-dokumen yang $\mathrm{L} / \mathrm{C}$ yang telah diserahkan padahal dokumen tersebut memiliki dicrepancy.

\section{Dasar Hukum}

Bahwa untuk melayani nasabah yang melaksanakan ekspor barang di PT. Bank BNI (Persero) Tbk terdapat ketentuan:

1. Buku Pedoman Tata Kerja Transaksi Ekspor Bank BNI; 
a. No.IN/0062/DLN tanggal 1 Mei 1997;

b. No. IN/0124/INT tanggal 18 September 1997;

c. No.0075/INT tanggal 29 April 1998;

d. No.IN/0100/INT tanggal 12 Juni 1998;

e. No.IN/0203/INT tanggal 29 Desember 1999.

Yang mengatur antara lain:

1) Eksportir haruslah nasabah debitur, dalam hal nasabah giran harus dilakukan risk (credit standing) assessment dan ditetapkan credit line sebagai batas maksimum outstanding proceeds export yang dapat dibeli oleh bank;

2) Cabang wajib melakukan pengecekan terhadap kebenaran dan kelengkapan dokumen ekspor;

3) Apabila di dalam pengecekan kebenaran dan kelengkapan dokumen terdapat penyimpangan/ discrepancy maka harus dilakukan perbaikan/amandemen, kecuali terhadap discrepancy yang bersifat uncorrectable maka tidak memenuhi syarat untuk diambil alih;

4) Untuk mengkoreksi atau memperbaiki dokumen dilakukan dengan cara menghubungi eksportir untuk melakukan perbaikan/koreksi dan atau penggantian dokumen. Jika pembetulan dokumen dilakukan dengan koreksi maka koreksi tersebut harus dibubuhi stempel koreksi dan dibubuhi tanda tangan pejabat yang berwenang;

5) Untuk Discrepancy yang sulit diperbaiki dapat menghubungi issuing bank perstected telex atau swift MT 799;

6) Ketentuan Negotiation under Letter of Indemnity (L/I) yaitu Apabila discrepancy tidak bisa dilakukan, maka dalam menegosiasi $\mathrm{L} / \mathrm{C}$ tersebut dokumen harus dikumpulkan terlebih dahulu atau neosiasi kurang dari $100 \%$ dengan jaminan Letter of Indemnity (L/I) dengan memperhatikan credit risk. Hal-hal yang dijadikan bahan pertimbangan adalah:

a) Eksportir adalah girant atau debitur;

b) Importir adalah regular buyer;

c) Frekuensi transaksi ekspor dan performance yang bersangkutan;

d) Bank pembuka L/C, koresponden/non koresponden.

7) Wesel ekspor berjangka yang didiskonto harus telah diaksep oleh issuing bank/confirming bank;

8) Jika diskonto sebelum ada akseptasi dari issuing bank/confirming bank maka: 
a) Dokumen $\mathrm{L} / \mathrm{C}$ harus telah sesuai dengan syarat $\mathrm{L} / \mathrm{C}$ (tidak ada discrepancy);

b) Dokumen L/C terdapat discrepancy maka dokumen tersebut harus mendapat persetujuan dari issuing bank.

9) Dokumen ekspor harus telah dikirimkan selambat-lambatnya keesokan hari kerja berikutnya setelah tanggal negosiasi wesel ekspor dengan menggunakan formulir Schedule of Remittance $(S / R)$ sebagai surat pengantar.

2. Surat Edaran Bank Indonesia No.29/58/ULN tanggal 31 Maret 1997 yang mengatur bahwa bank devisa wajib mengisi kolom G (kewajiban kepabeanan/pajak ekspor)pada formulir PEB sebagai bukti adanya realisasi pelaksanaan ekspor dan impor.

3. Uniform Customs and Practice for Documentary Credit of the International Chamber of Commerce Publication 500 (UCP 500) yang mengatur bahwa bank yang membayar, mengaksep, atau menegosiasi dokumen $\mathrm{L} / \mathrm{C}$, harus dilakukan pengecekan terhadap kebenaran dan kelengkapan dokumen ekspor tersebut. ${ }^{41}$ Apabila bank menerima dokumen yang menyimpang, bank berhak menolak untuk melakukan pembayaran, akseptasi, atau negosiasi tetapi sebaliknya bank berkewajiban untuk memberitahu beneficiary agar dokumen-dokumen tersebut diperbaiki atau meminta persetujuan applicant apakah ia menerima atau menolak dokumen yang menyimpang tersebut. ${ }^{42}$

Prosedur pengajuan L/C menurut Buku Pedoman Tata Kerja Transaksi Ekspor Bank BNI adalah:

1. ketika L/C diajukan ke BNI kemudian Asisten Bagian Luar Negeri bertugas menerima dan melakukan penelitian apakah L/C tersebut asli atau tidak;

2. kalau sudah dinyatakan asli kemudian pihak Bank BNI memberitahukan untuk melengkapi dokumen;

3. Setelah dokumen masuk ke Bank BNI kemudian dokumen tersebut diteliti apakah mengandung discrepancy atau tidak;

4. Setelah dilakukan penelitian kemudian hasilnya dituangkan dalam Kertas Kerja (work sheet) oleh Asisten Penyelia kemudian diberikan kepada CSMLN (Edy);

${ }^{41}$ UCP 500, Op. Cit., article 15.

${ }^{42}$ Ibid. article 16 (a), (b), (c). 
5. Jika dokumen tersebut terdapat discrepancy maka harus dimintakan keputusan kepada Pemimpin Cabang (Koesadiyuwono) dan jika dokumen clean maka cukup hanya sampai CSMLN (Edy) saja.

\section{Analisa Kasus}

\section{A. Terkait dengan Penerbitan $\mathrm{L} / \mathrm{C}$}

\section{Berdasarkan Buku Pedoman Tata Cara Transaksi Ekspor BNI}

Meskipun terdapat kejanggalan-kejanggalan dalam transaksi L/C tersebut, BNI Kebayoran Baru tetap melakukan negosiasi terhadap $37 \mathrm{~L} / \mathrm{C}$ tersebut. Seharusnya, sebelum dilakukan negosiasi terhadap $\mathrm{L} / \mathrm{C}$ yang mengandung discrepancy tersebut maka atas permintaan beneficiary dengan jaminan $L / /$ seharusnya menempuh tahapan sesui dengan ketentuan Buku Pedoman Tata Cara Transaksi Ekspor Bank BNI, adalah:

1) Pemimpin Cabang (Koesadiyuwono) dan CSMLN (Edy) menghubungi beneficiary untuk melakukan perbaikan atau amandemen atas penyimpangan dokumen dengan cara mengembalikan dokumen kepada beneficiary.

2) Bila tahapan ini tidak berhasil maka Koesadiyuwono dan Edy harus menghubungi issuing bank dari L/C tersebut untuk melakukan akseptasi (kesanggupan) sehingga issuing bank tersebut akan membayar BNI jika $\mathrm{L} / \mathrm{C}$ tersebut ternyata tidak terbayar (umpaid).

Terhadap permasalahan bahwa kedelapan perusahaan tersebut adalah nasabah giran, bukan nasabah debitur dan bukan eksportir seharusnya BNI Kebayoran Baru melakukan risk assesment (credit standing) dan ditetapkan credit line sebagai maksimum out standing proceeds ekspor yang dapat dibeli oleh nasabah. Tujuan risk assesment adalah menerapkan prinsip kehatihatian dalam melaksanakan transaksi ekspor dengan menggunakan L/C sebagaimana ditentukan dalam UU No.10 
Tahun 1998 tentang perbankan. ${ }^{43}$

\section{Berdasarkan Ketentuan Surat Edaran Bank Indonesia No.19/58/ULN}

Terkait dengan permasalahan bahwa kedelapan eksportir itu tidak pernah melakukan ekspor, Bank BNI sebagai bank devisa seharusnya mengisi kolom kewajiban kepabeanan/pajak ekspor yaitu Pemberitahuan Ekspor Barang (PEB) sebagai bukti adanya realisasi pelaksanaan ekspor dan impor Bank memang tidak bertanggung jawab terhadap keaslian dokumen akan tetapi bank harus mengetahui secara cermat dokumen-dokumen termasuk Pemberitahuan Ekspor Barang (PEB) yang diajukan.

\section{Berdasarkan Ketentuan UCP 500}

Bahwa sebelum bank mengambil alih wesel ekspor maka harus dilakukan pengecekan terhadap kebenaran dan kelengkapan dokumen ekspor tersebut. ${ }^{44}$ Apabila bank menerima dokumen yang menyimpang, bank berhak menolak untuk melakukan pembayaran, akseptasi, atau negosiasi tetapi sebaliknya bank berkewajiban untuk memberitahu beneficiary agar dokumendokumen tersebut diperbaiki atau meminta persetujuan applicant apakah ia menerima atau menolak dokumen yang menyimpang tersebut. ${ }^{45}$

Apabila beneficiary tetap meminta agar dokumen yang mengandung discrepancy tersebut agar tetap dibayar atau diambil alih oleh bank maka bank dapat membayar kepada beneficiary dengan syarat adanya jaminan dari beneficiary untuk membayar kembali jika issuing bank menolak untuk membayar atas dokumen yang diserahkan. ${ }^{46}$

${ }^{43}$ Indonesia (c), Undang-Undang Tentang Perubahan atas Undang-Undang Nomor 7 Tahun 1992 Tentang Perbankan, No.10 Tahun 1998, LN No. 182 Tahun 1998, TLN No. 3790, Pasal. 29.

\footnotetext{
${ }^{44}$ UCP 500, Op. Cit., article 15.

${ }^{45}$ Ibid. article 16 (a), (b), (c).

${ }^{46}$ Ibid., article $16(\mathrm{~g})$.
} 
Namun semua hal tersebut tidak dilakukan BNI Kebayoran Lama. Hal ini dibuktikan dengan masih ada dokumen-dokumen yang menyimpang namun tetap dilakukan negosiasi.

\section{B. Terkait dengan Trade Based Money Laundering}

Seperti yang telah dijelaskan sebelumnya bahwa BNI Kebayoran Baru tetap melakukan pembayaran dengan negosiasi atas $37 \mathrm{~L} / \mathrm{C}$ tersebut kepada Perusahaan Gramarindo Group sebagai beneficiary meskipun dalam L/C tersebut banyak kejanggalan-kejanggalan. Salah satunya perusahaan tersebut memperoleh dana pembayaran L/C tanpa adanya transaksi ekspor impor, maksudnya perusahaan tersebut tidak pernah melakukan ekspor. Meskipun kegiatan ekspor itu tidak ada, perusahaan tersebut membuat seolah-olah kegiatan ekspor itu ada untuk memalsukan dokumen-dokumen L/C. Tentunya perusahaan tersebut tidak bisa melakukan hal ini sendiri sehingga mereka membutuhkan bantuan pejabat bank yang akan membayar L/C tersebut, yaitu BNI Kebayoran Baru sebagai nominated bank yang melakukan negosiasi.

Berdasarkan hal di atas perusahaan tersebut memperoleh dana dari hasil pembayaran L/C berdasarkan dokumen-dokumen yang palsu. Kemudian mereka menikmati dana tersebut untuk kepantingan perusahaannya masing-masing. Tindakan untuk memperoleh dana dari hasil pemalsuan dokumen tersebut dikategorikan sebagai tindakan mencuci uang (money laundering). Namun, berdasarkan Putusan No.566/Pid.B/2004/PN.Jak-Sel., terdakwa Koesadiyuwono dan Eddy Santoso telah dihukum pidana korupsi berdasarkan pasal 2 ayat (1) jo pasal 18 UU No. 31 Tahun 1999 jo. UU No. 20 Tahun 2001 tentang Pemberantasan Tindak Pidana Korupsi.

\section{Berdasarkan Keputusan Kepala PPATK No.2/1/KEP.PPATK/2003 Tentang Pedoman Umum Pencegahan dan Pemberantasan Tindak Pidana Pencucian Uang bagi PJK}

Berdasarkan keputusan ini bahwa tindak pidana pencucian uang terdapat 2 tindak pidana yaitu tindak pidana umum dan tindak pidana pencucian uang. Dalam kasus ini tindak pidana umum yang dimaksud yaitu pemalsuan. Sedangkan tindak pidana pencucian uang yang dimaksud adalah memperoleh harta kekayaan dari tindak pidana. Dalam pencucian uang terdapat tahap-tahap yang dilakukan yaitu: 


\section{1) Placement}

Merupakan proses menempatkan harta kekayaan dalam sistem keuangan agar tidak menimbulkan kecurigaan bahwa uang tersebut diperoleh dari tindak kejahatan. Terkadang kegiatan ini diikuti dengan pengajuan kredit/pembiayaan untuk membiayai suatu usaha yang seolah-olah atau terkait dengan usaha yang sah.

Dalam kasus ini placement dilakukan dengan menempatkan dana pembayaran $\mathrm{L} / \mathrm{C}$ ke masing-masing rekening perusahaan Gramarindo Group atas dasar fasilitas kredit berupa L/C untuk membiayai kegiatan ekspor pasir yang tidak pernah ada.

2) Layering

Merupakan pemindahan dana dari beberapa rekening atau lokasi tertentu sebagai hasil placement ke tempat lain melalui serangkaian transaksi yang kompleks dan didesain untuk menyamarkan jejak sumber dana tersebut.

Dalam kasus ini, proses layering dapat berupa penggunaan dana dari masing-masing perusahaan yang tergabung dalam perusahaan Gramarindo Group untuk kegiatan usaha masing-masing perusahaan.

\section{3) Integration}

Merupakan proses menggunakan harta kekayaan yang telah dianggap sah, baik untuk dinikmati langsung, diinvestasikan ke dalam berbagai bentuk kekayaan material, maupun keuangan, dipergunakan untuk membiayai kegiatan bisnis yang sah, ataupun untuk membiayai kembali kegiatan tindak pidana.

Dalam kasus ini, proses integration terbukti dari penggunaan dana pembayaran $\mathrm{L} / \mathrm{C}$ untuk menutupi $\mathrm{L} / \mathrm{C}$ yang tidak terbayar/unpaid milik:

a) PT. Mahesa dengan Direktur Utama Rudi Sutopo,

b) PT. Petindo dendan Direktur Utama John Hamenda, dan

c) PT. Prasetya Cipta Tulada dengan direktur Yani Sumarsono. 
Selain itu juga untuk membiayai usaha marmer milik Maria di Kupang.

Berdasarkan kasus di atas dapat disimpulkan bahwa tindak pidana pencucian uang terjadi atas transaksi ekspor tidak pernah terjadi (ekspor fiktif). Meskipun begitu, ada tindak pidana pencucian uang yang terjadi atas transaksi ekspor impor. Dalam praktek Trade based Money Laundering tindakan ini merupakan under shipping of goods di mana perusahaan Gramarindo Group tidak pernah melakukan ekspor barang tetapi perusahaan tersebut membuat seolah-oleh terjadi ekspor barang dengan bantuan dari pejabat intern bank (orang dalam). Oleh karena itu, kasus L/C Fiktif BNI, dapat dikategorikan sebagai Trade based Money Laundering.

\section{Berdasarkan UU No. 25 Tahun 2003 tentang Perubahan Atas UU No. 15 Tahun 2002 tentang Tindak Pidana Pencucian Uang}

Berdasarkan penjelasan sebelumnya bahwa Gramarindo Group memperoleh harta kekayaan yang diperoleh dari hasil tindak pidana berupa pemalsuan di bidang perbankan. Hal tersebut sesuai dengan pasal 2 ayat (1) huruf f UU No. 25 Tahun 2003 yang berisi harta kekayaan tersebut diperoleh melalui tindak pidana di bidang perbankan berupa pemalsuan dokumen. ${ }^{47}$ Selain itu, harta kekayaan tersebut juga dapat dikatakan diperoleh dari hasil tindak pidana berupa korupsi, pemalsuan dan penggelapan.

\section{Penutup}

\section{A. Kesimpulan}

Berdasarkan hasil penulisan ini maka untuk menjawab pokok permasalahan yang ada, dapat diambil kesimpulan, adalah:

Penggunaan L/C dalam perdagangan ekspor impor dapat dianggap sebagai bentuk Trade based Money Laundering (pencucian uang) karena L/C sebagai alat pembayaran dalam transaksi ekspor impor disalahgunakan misalnya dengan cara melakukan mark up terhadap tagihan (invoice) ekspor impor sebagai dokumen yang diperlukan

${ }^{47}$ Indonesia (a), Op. Cit., Pasal. 2 ayat (1) huruf f. 
dalam L/C sehingga harga barang menjadi mahal. Dengan tagihan tersebut uang dapat dikirimkan antar negara dari satu perusahaan ke perusahaan lain dalam bentuk yang legal untuk dimasukan ke dalam sistem perbankan. Selain itu, penyalahgunaan $\mathrm{L} / \mathrm{C}$ untuk melakukan pencucian uang dapat berupa pemalsuan dokumen-dokumen $\mathrm{L} / \mathrm{C}$ (predicate offences) seolah-olah telah terjadi transaksi ekspor-impor.

Penggunaan L/C pada kasus L/C Fiktif BNI tidak dapat dikategorikan sebagai Trade based Money Laundering karena dalam kasus L/C Fiktif BNI, penyalahgunaan L/C dilakukan dengan cara mamalsukan dokumen-dokumen L/C bahkan memalsukan kegiatan ekspor-impor. Oleh karena itu kasus tersebut lebih tepat dikategorikan sebagai Money Laundering saja dengan tindak pidana awal (predicate offences) berupa pemalsuan (fraud). Sedangkan dalam Trade based Money Laundering, pencucian uang dilakukan berdasarkan adanya transaksi ekspor-impor. Beberapa tahap dalam melakukan Trade based Money Laundering yaitu Over and Under Invoicing of Goods and Services, Multiple Invoicing of Goods and Services, Over and Under Shipping of Goods and Services, False Discription of Goods and Services.

\section{B. Saran}

Berdasarkan penulisan ini, sistem keuangan dan transaksi keuangan sangat rentan terhadap tindak pidana pencucian uang karena tahap-tahap dalam tindakan pencucian uang sangat melibatkan sistem keuangan misalnya sistem perbankan dan transaksi keuangan misalnya transaksi $\mathrm{L} / \mathrm{C}$ sehingga transaksi $\mathrm{L} / \mathrm{C}$ dapat digunakan sebagai cara awal untuk melakukan pencucian uang. Untuk menghindari hal tersebut, setiap bank wajib menerapkan prinsip kehati-hatian bank (prudential banking) dalam melayani nasabah agar nasabah tersebut tidak menyalahgunakan fasilitas yang ada di bank dan bank tidak dijadikan sebagai sarana untuk menyamarkan harta kekayaan dari hasil tindak pidana. 


\section{Daftar Pustaka}

Andhibroto, Soepriyo. Letter of Credit: Dalam Teori dan Praktek, cet. 2 (Edisi revisi), Semarang: Dahara Prize, 1997.

Hadisoeprapto, Hartono. Kredit Berdokumen (Letter of Credit): Cara Pembayaran dalam Jual Beli Perniagaan, cet. 1, Yogyakarta: Liberty, 1984.

Hinkelman, Edward G. A Short Course in International Payments, California: World Trade Press, 1999.

Mamudji, Sri, dan Hang Raharjo. Metode Penelitian dan Penulisan Hukum, Jakarta: Badan Penerbit Fakultas Hukum Universitas Indonesia, 2005.

Mulyanto, "Pembuktian Terbalik dalam Tindak Pidana Pencucian Uang", Varia Peradilan: Majalah Hukum tahun ke XXII No. 254, (Januari 2007): 40 .

Purwosutjipto, H. M. N. Pengertian Hukum Dagang Indonesia: Hukum Jual Beli Perusahaan (4), cet. 5, Jakarta: Djambatan, 2003.

Rowe, Michael. Letter of Credit, London: Euromoney Publications, 1985.

Schutze, Rolf A. dan Gabriele Fontane, Documentary Credit Law Throughout the World, Paris: ICC Publishing, S.A., 2001.

\section{Peraturan Perundang-undangan}

Kitab Undang-undang Hukum Perdata [Burgelijk Wetboek], diterjemahkan oleh R . Subekti dan R. Tjitrosudibio, cet 33, Jakarta: Pradnya Paramita, 2003.

Undang-Undang Tentang Perubahan atas Undang-Undang Nomor 7 Tahun 1992 Tentang Perbankan, No:10 Tahun 1998, LN No. 182 Tahun 1998, TLN No. 3790.

Peraturan Pemerintah No.1 tahun 1982, Pasal.3 jo. Departemen Perdagangan dan Koperasi, Keputusan Menteri Perdagangan dan Koperasi tentang Tata Cara Pembayaran Ekspor dan Impor, No.27/KP/I/82. 


\section{Internet}

Idris, TEdy Ferdiansyah. "Buruknya Manajemen Risiko Biang Kerok Bobolnya L/C BNI", <http://www.kompas.com>, diakses tanggal 12 Maret 2007.

Ihsan, DEdy dan Doddy Aprilachtieno. "Di Mana Letak Kesalahan BNI? Bagian Pertama dari Dua Tulisan", <http://www.bisnis.com>, diakses tanggal 12 Maret 2007.

"Financial Action Task Force/Groupe d'Action Financiere, Trade based Money Laundering", <http://www.fatf-gafi.org/dataoecd/60/25/ 37038272.pdf>, diakses tanggal 27 Oktober 2007.

"International Chamber of Commerce: Indonesia National Committee", $<\mathrm{http} / / /$ iccindonesia.org/index.php?option=com_content\&task=view\&i $\mathrm{d}=14 \&$ Itemid=2>, diakses tanggal 22 November 2007.

"Pedoman Umum Pencegahan dan Pemberantasan Tindak Pidana Pencucian Uang bagi Penyedia Jasa keuangan", <http://www. bapepam.go.id/old/ragam/pedoman_pencucian_uang.pdf,>, diakses tanggal 8 Februari 2007. 